\title{
JOGOS DIGITAIS E SUPERDOTAÇÃO: UM ESTUDO COMPARATIVO
}

\author{
DIGITAL GAMES AND GIFTEDNESS: A COMPARATIVE STUDY \\ JUEGOS DIGITALES Y SUPERDOTACIÓN: UN ESTUDIO COMPARATIVO
}

\section{Ketilin Mayra Pedro ${ }^{1}$ \\ Miguel Claudio Moriel Chacon²}

\begin{abstract}
${ }^{1}$ Doutora em Educação pela UNESP. Docente do Centro de Ciências Humanas da Universidade do Sagrado Coração (UCS) - Bauru - SP - Brasil. ${ }^{2}$ Doutor em Educação Brasileira pela UNESP. Docente do Departamento de Educação Especial da Universidade Estadual Paulista (UNESP) - Marília - SP - Brasil.
\end{abstract}

Resumo: Os jogos digitais são considerados a atividade preferida de crianças e jovens, uma vez que estes possibilitam a interação com realidades virtuais e podem ser jogados por meio de qualquer dispositivo conectado na internet. Nessa perspectiva, o objetivo deste estudo foi verificar a maneira como estudantes com e sem comportamento superdotado interagem com jogos online. Trata-se de uma pesquisa comparativa que contou com a participação de 18 estudantes, do Ensino Fundamental, que foram divididos em dois grupos, sendo o G1 composto com estudantes superdotados e o G2 por estudantes sem essa característica. Todos os participantes realizaram uma atividade sobre jogos on-line, as ações dos estudantes foram analisadas com base na literatura da área e classificadas em três categorias: Desconhecimento, Tentativa e Erro e Consciente. Verificamos que tanto estudantes com e sem superdotação utilizaram os jogos digitais e softwares de uma maneira intuitiva, explorando-os pela "tentativa e erro" e sem intencionalidade. A utilização de jogos digitais no contexto educativo promove maior motivação e interesse na realização das atividades. Compreendemos que a adoção de jogos digitais no contexto educativo beneficiará a educação, uma vez que esses jogos se aproximam das preferências e das características dos nativos digitais e podem ter impactos positivos na aprendizagem de todos os estudantes, independentemente de suas especificidades.

Palavras-chave: Educação Especial; Superdotação; Jogos Digitais.

Abstract: Digital games are considered the preferred activity of children and young people, as they enable interaction with virtual realities and can be played through any device connected to the internet. From this perspective, the objective of this study was to verify the way students with and without giftedness interact with online games. This is a comparative research involving the participation of 18 students from an elementary school, who were divided into two groups, G1 was composed of gifted students and G2 was composed of students without this characteristic. All the participants performed an online gaming activity. The students' actions were analyzed, based on the literature in the area and classified into three categories: Lack of Knowledge, Trial and Error, and Awareness. We found that both gifted and non-gifted students used digital games and software in an intuitive way, exploiting them by "trial and error", unintentionally. The use of digital games in the educational context promotes greater motivation and interest in carrying out the activities. We understand that the adoption of digital games in the educational context will benefit education, since these games are in line with the preferences and characteristics of digital natives, and can have positive impacts on the learning of all students, regardless of their special characteristics.

Keywords: Special Education; Giftedness; Digital Games. 
Resumen: Los juegos digitales se consideran la actividad preferida de niños y jóvenes, ya que posibilitan la interacción con realidades virtuales y pueden ser jugados a través de cualquier dispositivo conectado a Internet. En esta perspectiva, el objetivo de este estudio fue verificar la manera en la que los estudiantes con y sin comportamiento superdotado interactúan con juegos digitales. Se trata de una investigación comparativa que contó con la participación de 18 estudiantes de la enseñanza primaria que se dividieron en dos grupos, siendo el G1 compuesto por estudiantes superdotados y el G2 por estudiantes sin esa característica. Todos los participantes realizaron una actividad sobre juegos en línea, las acciones de los estudiantes fueron analizadas con base en la literatura del área y clasificadas en tres categorías: Desconocimiento, Ensayo y error y Consciente. Hemos comprobado que tanto los estudiantes con y sin superdotación utilizaron los juegos digitales y software de una manera intuitiva, explorándolos por el "ensayo y error" y sin intencionalidad. La utilización de juegos digitales en el contexto educativo promueve mayor motivación e interés en la realización de las actividades. Comprendemos que la adopción de juegos digitales en el contexto educativo beneficiará la educación, ya que estos juegos se aproximan a las preferencias y características de los nativos digitales y pueden tener impactos positivos en el aprendizaje de todos los estudiantes, independientemente de sus especificidades.

Palabras clave: Educación Especial; Superdotación; Juegos Digitales.

\section{INTRODUÇÃO}

A superdotação é um fenômeno que se caracteriza pelo agrupamento de

[...] três grupos básicos de traços humanos: habilidades gerais e/ou específicas acima da média, altos níveis de comprometimento com a tarefa e altos níveis de criatividade. Crianças que manifestam ou são capazes de desenvolver uma interação entre os três grupos requerem uma ampla variedade de oportunidades educacionais, de recursos e de encorajamento acima e além daqueles providos ordinariamente por meio de programas regulares de instrução. (RENZULLI, 2014, p. 246).

Considerando as especificidades destes estudantes, há que se pensar sobre a relação destes com as Tecnologias Digitais da Informação e Comunicação (TDIC), uma vez que a sociedade contemporânea se caracteriza pelo uso constante da internet e dos seus recursos, interatividade e um enorme fluxo de informações. Cabe destacar que crianças e jovens são os grandes consumidores e usuários destes recursos.

De acordo com os teóricos norte-americanos Palfrey e Gasser (2011), as crianças e os jovens, que nasceram em uma era digital e desde a tenra idade interagem com os recursos tecnológicos, podem ser nomeados como nativos digitais.

Segundo Mattar (2010), Palfrey e Gasser (2011), Arruda (2011), os nativos digitais passam a maior parte do tempo conectados na internet, interagindo com variados jogos, vídeos e redes sociais. Estes têm como características a realização de múltiplas tarefas simultaneamente, exploração das TDIC de maneira intuitiva e necessidade constante de interatividade.

Neste contexto, observa-se que um dos setores que mais cresce na indústria do entretenimento são osjogos digitais para computadores. De acordo com Prensky (2001), a maioria dos jovens gasta mais tempo com os jogos digitais de que com as atividades escolares.

A pesquisa TIC Kids Online Brasil (2015) revela que 84\% das crianças e dos adolescentes brasileiros, entre 9 e 17 anos, utilizam jogos on-line. Autores como Mattar (2010), Arruda (2011), Almeida e Costa (2012) apontam em suas pesquisas a preferência dos estudantes por jogos on-line e a necessidade de incorporar estes recursos também no contexto educacional. 
Os jogos digitais proporcionam interação com mundos e realidades virtuais que outros tipos de jogos não propiciam, por conseguinte, crianças e adolescentes que passam muito tempo na internet fazem dos jogos a atividade principal no mundo virtual (SAVI; ULBRICHT, 2008; FROSI; SCHLEMMER, 2010; ALCÂNTARA; OSÓRIO, 2014).

Teóricos da área da superdotação destacam a necessidade de se pesquisar e refletir sobre o modo como os estudantes superdotados exploram esses recursos. Freitas (2012, p. 208) aponta que as TDIC podem funcionar como facilitadoras do processo de ensinoaprendizagem, mas que a mediação é imprescindível para que os recursos tecnológicos sejam usados de maneira adequada. Nesse sentido, a autora ressalta que "[...] estas tecnologias são muito importantes para o desenvolvimento destes sujeitos, porém devem ser mediadas e canalizadas para o progresso pessoal e científico".

Acredita-se que as TDIC são valiosas ferramentas intelectuais para enriquecimento de estudantes superdotados; no entanto, é necessário identificar as habilidades que são específicas desses estudantes e aquelas que são comuns a todos os nativos digitais, a fim de que se possa orientá-los e ajudá-los a desenvolver competências digitais para uma utilização segura e produtiva da tecnologia.

Nessa perspectiva, acredita-se que, quando os jogos são utilizados com intencionalidade pedagógica, estes podem caracterizar-se como valiosas ferramentas intelectuais que podem enriquecer o desenvolvimento cognitivo dos estudantes. Sendo assim, o objetivo deste estudo é verificar a maneira como estudantes com e sem comportamento superdotado interagem com jogos on-line.

\section{Método}

Este trabalho apresenta um recorte da pesquisa de doutorado de Pedro (2016), que teve como objetivo descrever comparativamente o uso que os estudantes com comportamento superdotado, dos anos iniciais e finais do Ensino Fundamental, fazem das TDIC.

O grupo de estudantes superdotados (G1) foi composto com base nos dados do projeto de extensão "Programa de Atenção a estudantes Precoces com Comportamento Superdotado (PAPCS)", da Faculdade de Filosofia e Ciências da UNESP/Marília. A partir dos estudantes deste grupo, foram selecionadas as escolas em que se buscaram os participantes do grupo comparativo (G2), cujas características eram pareadas aos estudantes do G1 (gênero, idade, ano escolar e condições de acesso às TDIC), exceto a variável superdotação. A caracterização dos participantes de ambos os grupos está apresentada no Quadro 01.

Quadro 1 - Pareamento dos grupos 1 e 2

\begin{tabular}{|l|l|l|l|l|}
\hline \multicolumn{2}{|c|}{ G1 G2 } & \multicolumn{1}{c|}{ Gênero } & Idade & \multicolumn{1}{c|}{ Ano Escolar } \\
\hline FP & L & Masculino & 6 & $1^{\circ}$ \\
\hline V & IC & Feminino & 6 & $1^{\circ}$ \\
\hline DA & MR & Masculino & 8 & $2^{\circ}$ \\
\hline CV & R & Masculino & 8 & $3^{\circ}$ \\
\hline VH & FA & Masculino & 10 & $4^{\circ}$ \\
\hline
\end{tabular}




\begin{tabular}{|l|l|l|l|l|}
\hline C & G & Feminino & 10 & $5^{\circ}$ \\
\hline ES & RZ & Masculino & 11 & $5^{\circ}$ \\
\hline FB & LM & Masculino & 10 & $5^{\circ}$ \\
\hline M & PH & Masculino & 11 & $5^{\circ}$ \\
\hline PD & IA & Masculino & 11 & $5^{\circ}$ \\
\hline VA & JP & Masculino & 11 & $5^{\circ}$ \\
\hline BG & N & Feminino & 11 & $6^{\circ}$ \\
\hline D & TS & Masculino & 11 & $6^{\circ}$ \\
\hline GS & AJV & Feminino & 13 & $8^{\circ}$ \\
\hline IS & AJ & Feminino & 13 & $8^{\circ}$ \\
\hline PE & W & Masculino & 13 & $8^{\circ}$ \\
\hline RC & TG & Masculino & 13 & $8^{\circ}$ \\
\hline DE & LL & Masculino & 14 & $9^{\circ}$ \\
\hline
\end{tabular}

Fonte: Elaboração própria.

Os participantes da pesquisa realizaram um Programa de Atividades Dirigidas, que contemplava a utilização da internet e variados softwares. Neste trabalho serão apresentados os dados referentes à atividade de Jogos On-line.

Optou-se por essa atividade ao se observar a disseminação de jogos on-line para diferentes dispositivos e o interesse de crianças e adolescentes por essa modalidade. Para os estudantes dos anos iniciais ( $1^{\text {a }}$ ao $5^{\circ}$ ano), foram predefinidos três jogos on-line, para que fosse observada a interação dos estudantes com os mesmos, razão pela qual essa atividade foi dividida em quatro partes: 1 . Acessar o site Iguinho (www.iguinho.com.br); neste site era solicitado o acesso a três jogos: 2. "Comida ao Alvo"; 3. "Corrida da Zuzubalândia"; 4. "Jogo das Receitas". Cabe ressaltar que esses jogos foram selecionados por apresentarem instruções de como deveriam ser jogados - em dois desses jogos, as mesmas figuravam na tela inicial, ao passo que, no outro, era necessário clicar sobre a palavra "Instruções" - e por explorarem habilidades que contemplam as variadas faixas etárias compreendidas nos anos iniciais. Nas Figuras 1 e 2 estão, respectivamente, o objetivo e a interface dos jogos.

Figura 1 - Tela inicial e instruções dos jogos on-line

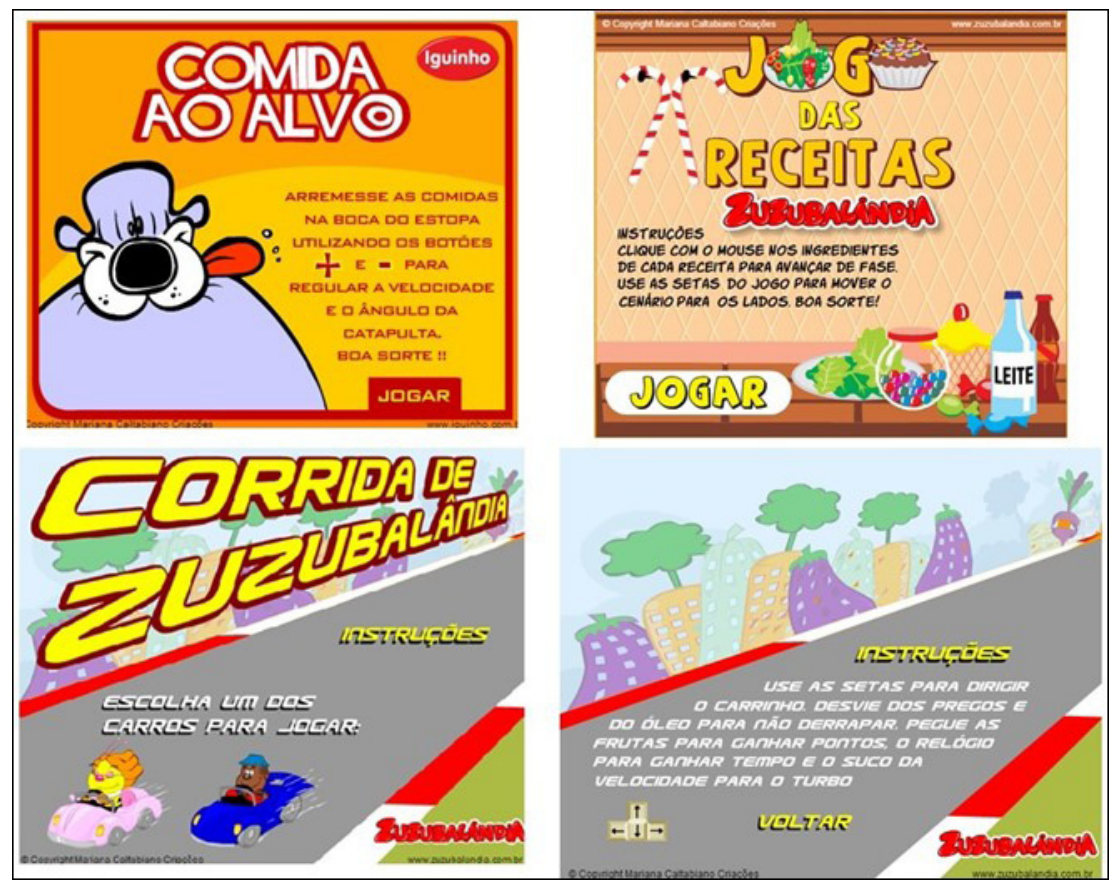

Fonte: Elaboração própria. 
Figura 2 - Interface dos jogos on-line
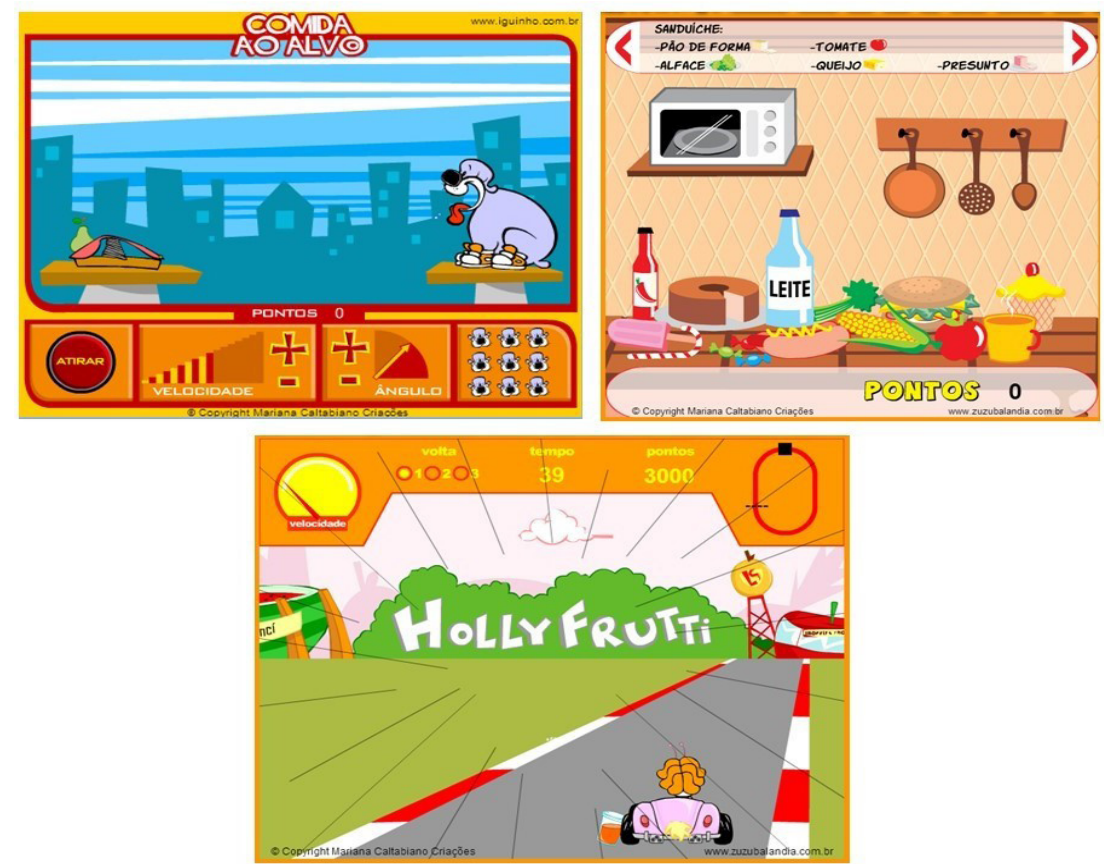

Fonte: Elaboração própria.

Para os estudantes dos anos finais ( $6^{\circ}$ ao $9^{\circ}$ ano), selecionaram-se o jogo Letroca e o software HagáQuê: o primeiro é um jogo que trabalha aspectos da Língua Portuguesa, cujo jogador deve formar o maior número de palavras, no menor tempo possível, usando as letras que foram sorteadas pelo jogo; o segundo constitui uma interface que possibilita a criação de histórias em quadrinhos. A Figura 3 apresenta as interfaces do Letroca e HagáQuê.

Figura 3 - Interface dos jogos Letroca e HagáQuê

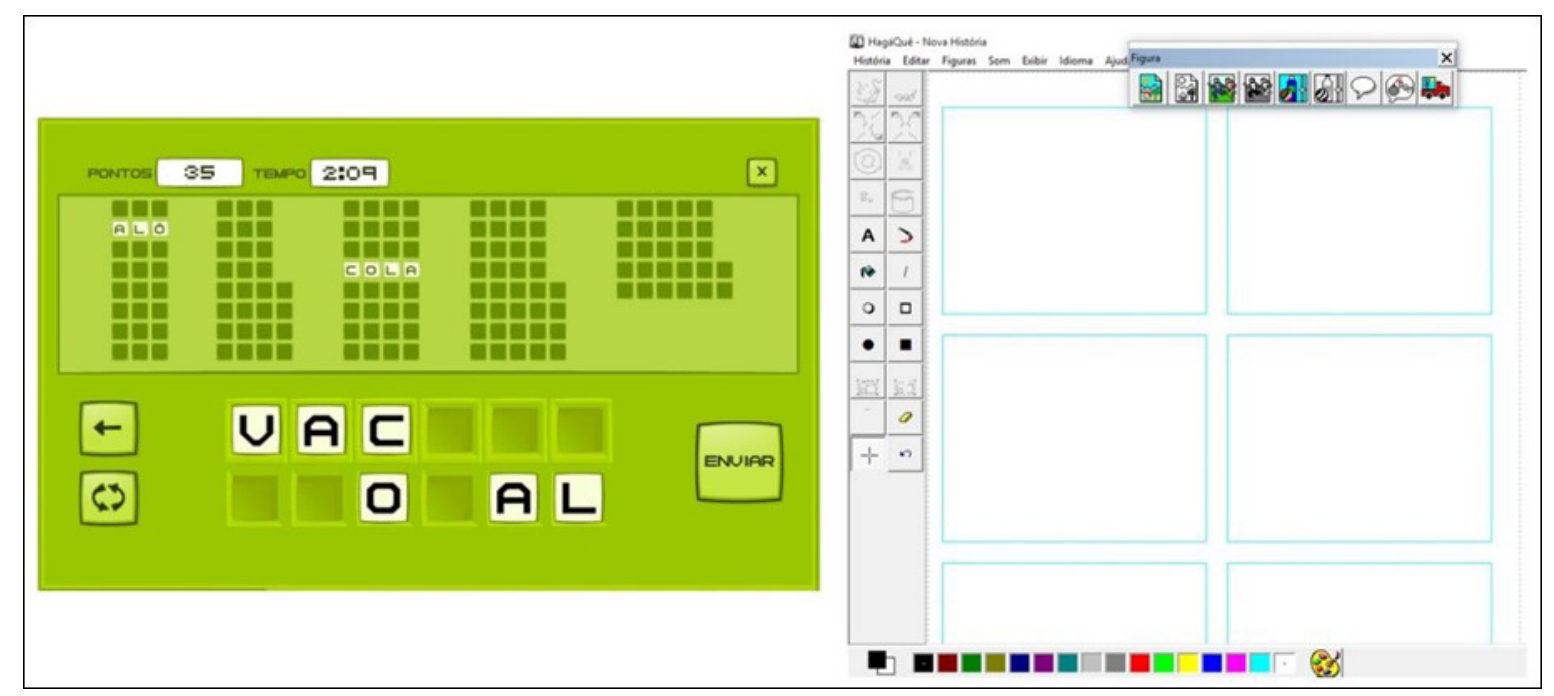

Fonte: Elaboração própria.

Para fins de análise dos dados, classificou-se a ação dos estudantes em três categorias:

1-Desconhecimento - tem certa familiaridade com o computador, mas ainda não realiza independentemente a maioria das atividades;

2-Tentativa e erro - explora os recursos de maneira aleatória e não possui um rumo pré-determinado, fazendo com que as dificuldades se transformem em aprendizado;

3-Consciente - passa pela experiência do aprendizado e possui familiaridade com os ambientes informacionais, tornando suas ações mais orientadas e seguras, na medida em que recebe poucos esclarecimentos. (PEDRO, 2016, p. 93). 
No próximo item, serão apresentados os dados coletados em quadros e a discussão dos mesmos com base no referencial teórico da área.

\section{Resultados e Discussões}

Apresentar-se-á a seguir a descrição da atividade realizada pelos estudantes dos anos iniciais e finais do Ensino Fundamental. O Quadro 2 apresenta o desenvolvimento da atividade sobre jogos on-line pelos estudantes dos anos iniciais.

Quadro 2 - Desenvolvimento da atividade - anos iniciais

\section{Atividade Jogos On-line (anos iniciais)}

G1

$1^{\circ}$ ano

FP não leu as instruções de nenhum dos jogos recomendados. No primeiro FP fez a primeira tentativa e logo percebeu que era necessário alterar o ângulo e a velocidade para acertar a comida, mesmo assim, teve dificuldades para fazer o primeiro acerto. No segundo FP jogou sem dificuldades e no terceiro foi necessário esclarecimento para que o mesmo compreendesse o jogo. (2)

$\checkmark$ necessitou de esclarecimento e ajuda para jogá-los corretamente (na época da pesquisa não eram alfabéticas). (1)

$2^{\circ}$ ano

DA leu as instruções do primeiro jogo e o explorou corretamente. No segundo e no terceiro jogo DA não leu as instruções e precisou de ajuda. (2)

$3^{\circ}$ ano

CV leu as instruções do primeiro jogo e não teve dificuldades para jogá-lo. No segundo e no terceiro jogo as instruções não foram lidas, sendo que no último CV precisou

de esclarecimento. (2)
G2

L não leu as instruções de nenhum dos jogos recomendados. No primeiro ficou jogando por meio da tentativa e erro, foi necessário intervenção para que compreendesse que era necessário ajustar a velocidade e o ângulo em cada jogada. No segundo jogo $L$ não teve dificuldades para compreender o objetivo do jogo e jogou corretamente, no terceiro foi necessário esclarecimento e ajuda para jogar corretamente. (2)

IC necessitou de esclarecimento e ajuda para jogá-los corretamente (na época da pesquisa não eram alfabéticas). (1)

MR não leu as instruções de nenhum dos jogos recomendados, sendo que foi necessário ajuda durante o terceiro jogo, mesmo assim MR apertava nos itens apresentados aleatoriamente. (2)

$R$ leu as instruções de todos os jogos, sendo que no primeiro e no último foi necessário ajuda para que o estudante pudesse jogar corretamente. (2) 
VH leu as instruções do primeiro jogo, mas foi necessário ajuda para que pudesse jogar corretamente. No segundo e no terceiro jogo as instruções não foram lidas e precisou de ajuda para jogá-los. (2)
FA leu as instruções do primeiro e do terceiro jogo, sendo que no último precisou de ajuda para jogá-lo. No segundo jogo as instruções não foram lidas, mas foi jogado corretamente. (2)

$5^{\circ}$ ano

C leu as instruções de todos os jogos, sendo que no primeiro e no segundo rapidamente compreendeu o objetivo dos mesmos. No último jogo foi necessário esclarecimento. (3)

ES leu as instruções de todos os jogos, sendo que no primeiro foram necessárias algumas tentativas para acertar o alvo, no segundo foi preciso reler as instruções (o aluno usava os comandos do mouse em vez do teclado) e no último necessitou de esclarecimento. (2)

FB não leu as instruções em nenhum dos jogos, sendo que no primeiro e no segundo jogo foram necessárias várias tentativas para compreender o objetivo do mesmo; e no terceiro jogo necessário esclarecimento e ajuda para tanto. (2)

$M$ não leu as instruções de nenhum dos jogos selecionados, sendo que no primeiro e no segundo M não teve dificuldades; e o terceiro foram necessárias algumas tentativas para que pudesse compreender o jogo. (2)

PD leu as instruções do primeiro jogo e não teve dificuldades, no segundo PD não leu as instruções e disse que não era necessário por ser um jogo de corrida, no terceiro as instruções foram lidas, mas PD precisou de esclarecimento. (3)

VA leu as instruções do primeiro jogo e não teve dificuldades. No segundo e no terceiro, as instruções não foram lidas, sendo que no último foi necessário esclarecimento. (3)
G não leu as instruções de nenhum dos jogos selecionados, sendo que nos dois primeiros explorou pela tentativa e erro, e no último foi necessário esclarecimento. (2)

$R Z$ não leu as instruções de nenhum dos jogos elencados, sendo que no primeiro explorou pela tentativa e erro, no segundo rapidamente descobriu os comandos e no terceiro precisou de esclarecimento. (2)

LM não leu as instruções de nenhum dos jogos selecionados, sendo que o primeiro foi explorado pela tentativa e erro, no segundo LM não teve dificuldades e no terceiro foi necessário ajuda. (2)

$\mathrm{PH}$ não leu as instruções de nenhum dos jogos selecionados, sendo que no primeiro jogo foram necessárias algumas tentativas para acertar o alvo, no segundo $\mathrm{PH}$ não teve dificuldades e no terceiro foi necessário esclarecimento. (2)

IA não leu as instruções de nenhum dos jogos selecionados, no primeiro teve dificuldades para configurar o ângulo e a velocidade, no segundo jogou sem dificuldades e no terceiro precisou de esclarecimento e ajuda. (2)

JP leu as instruções de todos os jogos, sendo que no primeiro houve dificuldades para configurar o ângulo e a velocidade e no terceiro foi necessário esclarecimento. (2) 
Quanto à leitura das instruções, destaca-se que a maioria dos estudantes não efetuou a leitura antes de iniciar os jogos. No jogo Comida ao Alvo, as instruções estavam na tela inicial e dez estudantes ( $G 1=3$ e $G 2=7$ ) não fizeram a leitura, fato que os levou a fazer uso intuitivo da ferramenta, o que demandou, em alguns casos, várias tentativas até acertar o alvo.

Em Corrida de Zuzubalândia, era necessário clicar na palavra "Instruções", para que esse item fosse aberto, no entanto 16 estudantes $(G 1=8$ e $G 2=8)$ não as leram. Ora, o objetivo desse jogo era claro, por se tratar de um jogo de corrida, modalidade com a qual a maioria dos participantes estava familiarizada, sendo que as dificuldades encontradas por alguns estavam em descobrir quais botões controlavam o carro de corrida. Acredita-se que o fato de a maioria dos estudantes não ter solicitado ajuda ou esclarecimento nesse jogo se justifica pelo modo como tais jogos são acionados, porque geralmente o comando do veículo acontece pelos botões do teclado.

No Jogo das Receitas, as instruções estavam na tela inicial, mas 14 estudantes não efetuaram sua leitura ( $G 1=7$ e G2=7); embora o jogo fosse simples, nas instruções havia uma "dica" importante sobre como mover o cenário em busca de mais ingredientes, ação para a qual a maioria dos estudantes apresentou dificuldade e foi necessário esclarecimento.

Identificou-se que a interatividade proporcionada pelos jogos, a empolgação provocada por estes e a segurança que os nativos digitais sentem na internet favorecem o sentimento de confiança em explorar um jogo sem conhecer as regras, mesmo porque o fazem livremente e realizam quantas tentativas forem necessárias para aprender a jogar corretamente. Considerase que essa conduta prejudica o aproveitamento dos jogos, visto que eles desenvolvem habilidades variadas e estimulam o raciocínio e, quando jogados com intencionalidade, podem desafiar mais o usuário. Sobre a utilização de jogos digitais por estudantes superdotados, Mulrine (2007) e Shamblin (2011) asseveram que estes são excelentes recursos pedagógicos, quando são desafiadores e envolventes. Hung et al. (2012) complementam essa afirmação, ao destacar que o uso das TDIC no contexto educativo sem objetivos e estratégias eficazes pode ser decepcionante, enfatizando a importância de uma escolha assertiva dos recursos que serão adotados na prática pedagógica.

Observamos que, embora todos os jogos contivessem instruções, em alguns casos estas não foram suficientes para que o estudante compreendesse seu objetivo, reforçando a importância da mediação e da intencionalidade na exploração de recursos como este (DURAN, 2010).

Analisando ambos os grupos, notou-se que apenas três estudantes leram todas as instruções; dentre estes, dois do $\mathrm{G} 1$, que têm como característica tranquilidade e envolvimento no momento de realizar qualquer atividade, características estas que não são percebidas na maioria dos nativos digitais (VEEN; VRAKKING, 2009). A leitura de todas as instruções possibilitou uma exploração dos jogos mais intencional e assertiva, embora alguns dos estudantes tenham requerido ajuda ou esclarecimento no último jogo, porque as suas instruções não eram suficientemente claras.

A rapidez com que os nativos digitais realizam ações na internet ficou evidente, nessa atividade, sendo que 18 estudantes acessaram o site de jogos por meio do Google e não pela 
barra de endereços, característica esta que é percebida em estudantes nativos digitais, uma vez que não é mais necessário anotar os endereços dos sites, pois somente com o nome do mesmo é possível localizar rapidamente por meio de um buscador.

Em relação à categorização da ação dos estudantes, observou-se que apenas três estudantes do G1 (C, PD e VA) as tiveram qualificadas como 'Conscientes', demonstrando que, embora os estudantes estejam familiarizados com jogos on-line, estes fazem uma utilização intuitiva do jogo, até que consigam alcançar o objetivo, ação esta que evita o caráter educativo do jogo, de sorte que as ações são aleatórias e, muitas vezes, o estudante não reflete sobre o que está fazendo. Sobre esse tipo de exploração, Pescador (2012) revela que o emprego do jogo de forma correta acontece acidentalmente, porque os estudantes descobrem as regras conforme exploram o jogo e, quando não obtêm sucesso, tentam de outra maneira.

No Quadro 3, é exposto o desenvolvimento das atividades com softwares e sites educativos pelos estudantes dos anos finais.

Quadro 3-Desenvolvimento da atividade - anos finais

\section{Atividade Softwares e Sites Educativos (anos finais)}

G1 G2

\section{$6^{\circ}$ ano}

BG acessou o jogo Letroca fazendo uma busca na barra de endereços, a estudante rapidamente compreendeu o jogo e encontrou as maiores palavras da rodada. Em relação ao software HagáQuê, BG acessou por meio do menu 'Iniciar' e teve dificuldades para montar um quadrinho mesmo após o

esclarecimento que era preciso clicar no item cenário e depois posicionar o mouse sobre o quadrinho, foi necessário ajuda para que diminuíssem as figuras e alterasse o lado das mesmas. (2)

\section{D precisou de ajuda e esclarecimento para} acessar e jogar Letroca e também utilizar o software HagáQuê. (1)

$\mathrm{N}$ acessou o jogo Letroca por meio do Google, a estudante compreendeu rapidamente o objetivo do jogo, embora tenha formado poucas palavras nas primeiras rodadas jogadas. $\mathrm{N}$ precisou de ajuda para localizar o software HagáQuê e realizou toda a atividade corretamente, precisou de ajuda para diminuir a figura. (3)

TH acessou o Letroca por meio do Google e precisou de esclarecimento para utilizar o jogo. O software HagáQuê foi acessado pelo menu 'Iniciar', sendo necessário esclarecimento para inserir os objetos. (1)

$8^{\circ}$ ano

GS acessou o Letroca por meio do Google, inicialmente a estudante teve dificuldades, foi esclarecido que nem todas as letras teriam que ser utilizadas para formar as palavras, após isso GS jogou sem dificuldades. O HagáQuê foi acessado por meio do menu 'Iniciar', foi necessário esclarecimento e ajuda para que a estudante manipulasse os objetos e elaborasse o quadrinho. (2)
AJV acessou o Letroca por meio do Google, inicialmente a aluna precisou de esclarecimento e ajuda para realizar o jogo, mas na segunda rodada não foi necessário ajuda. Em relação ao HagáQuê, localizou o software utilizando o 'Localizar', explorou os recursos e conseguiu utilizar os objetos e elaborar o quadrinho. (3) 
IS acessou o site Letroca pelo Google e soube utilizar o jogo sem dificuldades. Para localizar o jogo HagáQuê, utilizou a ferramenta 'Localizar', a estudante explorou as ferramentas sem dificuldades. (3)

PE acessou o jogo Letroca por meio da barra de endereços e apresentou dificuldades nas primeiras rodadas. O software HagáQuê foi acessado por meio do 'Localizar' e foi preciso ajuda para que PE explorasse os recursos. (1)

RC acessou o jogo Letroca por meio da barra de endereços e realizou a atividade sem dificuldades. O software HagáQuê foi acessado por meio do 'Localizar', RC precisou de esclarecimentos para compreender o uso dos recursos, depois o aluno realizou as atividades sem dificuldades. (3)
AJ acessou o Letroca usando a barra de endereços e após algumas tentativas conseguiu compreender o jogo. Utilizou o software HagáQuê por meio da ferramenta 'Localizar', a estudante explorou as ferramentas sem dificuldades. (3)

W acessou o jogo Letroca por meio da barra de endereços, o estudante precisou de ajuda para formar as primeiras palavras, mas depois concluiu a atividade de maneira independente. O software HagáQuê foi acessado por meio do 'Localizar', W não teve dificuldades para realizar a atividade. (3)

TG acessou o jogo Letroca pelo Google, o estudante teve dificuldades para formar as palavras, embora tenha entendido o objetivo do jogo. O software HagáQuê foi acessado por meio do 'Localizar', TG precisou de esclarecimento para utilizar os recursos e realizar a atividade. (2)

$9^{\circ}$ ano

DE acessou o jogo Letroca utilizando o Google e após o esclarecimento o estudante realizou o jogo sem dificuldades. Para acessar o HagáQuê, fez uma busca pelo 'Localizar', necessitou de esclarecimento para inserir objetos nos quadrinhos (não clicava sobre o quadro) e também para localizar a ferramenta que virava as imagens. (2)

LL acessou o Jogo Letroca por meio do Google, após o esclarecimento o estudante realizou o jogo sem dificuldades. O software HagáQuê foi acessado por meio do 'Localizar'. O estudante inicialmente precisou de ajuda para inserir o texto no quadrinho. (2)

Fonte: Elaboração própria.

A categorização da ação dos estudantes, nessa atividade, foi variada, sendo que três estudantes apresentaram ações de Desconhecimento ( $G 1=\mathrm{D}$ e PE; G2= TS), cinco de Tentativa e Erro (G1= BG, GS e DE; G2= TG e LL) e seis Conscientes (G1= IS e RC; G2= N, AJV, AJ e $W)$. Nessa atividade, os estudantes do G2 tiveram mais ações Conscientes, mostrando mais habilidades no acesso e exploração dos jogos utilizados.

Na exploração do jogo Letroca, notou-se que nenhum dos estudantes acessou o item "como jogar", a maioria explorou o jogo intuitivamente e descobria por "tentativa e erro" a maneira correta de jogá-lo. Identificou-se que, quando um software se assemelha a outro de que os estudantes têm conhecimento, como no caso do HagáQuê, muito semelhante ao aplicativo Paint, os usuários testavam as possibilidades até conseguir executar e/ou encontrar aquilo que desejavam. 
Nessa perspectiva e com base nos achados de Duran (2010), reitera-se a importância do mediador durante a exploração desse software, para que o estudante possa de fato atingir o objetivo da atividade e refletir sobre a ação que está sendo executada. Sobre a mediação nas atividades que utilizam as TDIC, Illera e Roig (2010) afirmam que as atividades que requerem um domínio técnico não podem ser aprendidas de maneira prática ou pela tentativa e erro, mas devem ser mediadas pelo professor, que oferecerá orientações pontuais e específicas, a fim de que o estudante desenvolva habilidades e autonomia para posteriormente realizá-las de modo independente.

Refletindo sobre os aspectos positivos de usar jogos digitais, Bakar et al. (2005), Arruda (2011), Gómez (2015) sustentam que, quando crianças e adolescentes jogam para se divertir, também estão estimulando e desenvolvendo aspectos estruturais, interesses por resoluções de problemas e desenvolvendo habilidades exigidas na era digital, elementos estes que podem ser aproveitados e incentivados dentro do ambiente escolar no processo de ensino-aprendizagem. Diante disso, é cada vez mais necessário conhecer e considerar os interesses dos nativos digitais, bem como suas estratégias de comunicação e aprendizagem, para que se possa proporcionar aos estudantes aprendizagem significativa mais próxima do seu cotidiano e que o capacite a viver em uma sociedade marcada pela liquidez e pela interatividade.

A utilização de jogos e de aplicativos de elaboração, como o HagáQuê, estimula o desenvolvimento da competência digital associada à resolução de problemas (LUEG, 2014). Tais recursos estimulam o pensamento criativo e, quando são usados em rede ou em grupos, favorecem a resolução de problemas de maneira colaborativa.

\section{Considerações Finais}

Ao se recuperar o objetivo que norteou o desenvolvimento deste trabalho, verificou-se que tanto estudantes com e sem superdotação utilizaram os jogos digitais de uma maneira intuitiva, explorando-os pela "tentativa e erro" e sem intencionalidade.

Neste sentido, acredita-se que é cada vez mais necessário instrumentalizar os estudantes para a utilização das TDIC e incorporá-las nos contextos escolares, de modo que essas sejam utilizadas de maneira intencional e enriqueçam o processo de ensino-aprendizagem.

A utilização de jogos digitais no contexto educativo promove maior motivação e interesse na realização das atividades, sendo que coloca o estudante no papel de protagonista do processo de ensino-aprendizagem. Nessa perspectiva, traz-se o conceito de Gamification, que se mostra como uma nova tendência, que consiste no emprego de jogos em situações que não são puramente de entretenimento.

Compreende-se que essa nova vertente na adoção de jogos digitais beneficiará inúmeros campos de atuação, principalmente a educação, uma vez que esses jogos se aproximam das preferências e das características dos nativos digitais e podem ter impactos positivos na aprendizagem de todos os estudantes, independentemente de suas especificidades. 
ALCÂNTARA, A.; OSÓRIO, A. Um caso lúdico: brincar no Facebook. In: PORTO, C.; SANTOS, E. (Org.). Facebook e educação: publicar, curtir, compartilhar. Campina Grande: EDUEPB, 2014. p. 113-130.

ALMEIDA, A. C.; COSTA, E. Jogos na educação e na formação: o projeto GREAT. In: CARVALHO, A. A. A. (Org.). Aprender na Era Digital: jogos e mobile-learning. Portugal: De Facto Editores, 2012. p. 29-64.

ARRUDA, E. P. Aprendizagens e jogos digitais. Campinas: Editora Alínea, 2011.

BAKAR, Y.; INAL, Y.; CAGILTAY, K. Use of commercial games for educational purposes: will today's teacher candidates use them in the future? In: CGames 2005. $7^{\mathrm{a}}$ Internacional Conference on Computer Games. Angouleme, 2005. p. 250-257.

COMITE GESTOR DA INTERNET NO BRASIL. Pesquisa sobre o uso da internet por crianças e adolescentes no Brasil - TIC Kids On-line Brasil 2015. São Paulo: CGI.br, 2016. Disponível em: http://www. cetic.br/publicacoes/indice/page:2. Acesso em: 04 fev. 2017.

DURAN, D. Letramento digital e desenvolvimento: das afirmações às interrogações. São Paulo: Hucitec, 2010.

FREITAS, S. N. Altas Habilidades/superdotação: processos de mediação com a utilização das tecnologias de informação e comunicação. In: GIROTO, C. R. M.; POKER, R. B.; OMOTE, S. (Org.). As tecnologias nas práticas pedagógicas inclusivas. Marília: Oficina Universitária; São Paulo: Cultura Acadêmica, 2012. p.185-210.

FROSI, F.; SCHLEMMER, E. Jogos Digitais no Contexto Escolar: desafios e possibilidades para a prática docente. In: IX SBGames. Florianópolis. Anais...2010. Disponível em: http://www.sbgames.org/papers/sbgames10/culture/full/full13.pdf . Acesso em: 9 fev. 2016.

GÓMEZ, A. I. P. Educação na Era Digital: a escola educativa. Porto Alegre: Penso, 2015.

HUNG, P.; HWANG, G.; SU, I.; LIN, I. A Concept-Map Integrated Dynamic Assessment System for Improving Ecology Observation Competences in Mobile Learning Activities. Turkish Online Journal of Educational Technology - TOJET, v.11, n.1, p.10-19. 2012. Disponível em: http://files.eric.ed.gov/fulltext/ EJ976563.pdf. Acesso em: 29 dez. 2015.

ILLERA, J. L. R.; ROIG, A. E. Ensino e aprendizagem de competência comunicacionais em ambientes virtuais. In: COLL, C.; MONEREO, C. (Org.). Psicologia da Educação Virtual: aprender e ensinar com as Tecnologias da Informação e da Comunicação. Porto Alegre: Artmed, 2010. p. 329-345.

LUEG, C. F. Competencia digital docente: desempeños didácticos en la formación incial del profesorado. Revista Científica de Educación y Comunicación. Educom: Cádiz-Espanha, nov., 2014, p. 55-71.

MATTAR, J. Games em Educação: como os nativos digitais aprendem. São Paulo: Pearson Prentice Hall, 2010.

MULRINE, C. F. Creating a Virtual Learning Environment for Gifted and Talented Learners. Gifted Child Today, v.30, n. 2, p. 37-40. 2007. Disponível em: http://files.eric.ed.gov/fulltext/EJ756553.pdf. Acesso em: 6 dez. 2015.

PALFREY, J; GASSER, U. Nascidos na era digital: entendendo a primeira geração dos nativos digitais. Porto Alegre: Artmed, 2011.

PEDRO, K. M. Estudo comparativo entre nativos digitais sem e com precocidade e comportamento dotado. (Doutorado em Educação) - Faculdade de Filosofia e Ciências, Unesp/Marília, 2016. Disponível em: http://repositorio.unesp.br/ handle/11449/143469. Acesso em: 01 set. 2016. 
PESCADOR, C. M. Alunos nativos digitais e professores imigrante digitais. In: SOARES, E. M. S.; PETARNELLA, L. (Org.). Cotidiano escolar e tecnologias: tendências e perspectivas. Campinas: Editora Alínea, 2012. p. 15-30.

PRENSKY, M. Digital Natives, digital immigrants. On the Horizon, NCB University Press, v. 9, n. 5, out. 2001.

RENZULLI, J. S. A concepção de superdotação no modelo dos três anéis: Um modelo de desenvolvimento para a promoção da produtividade criativa. In: VIRGOLIM, A. M. R.; KONKIEWITZ, E. C. (Org.). Altas Habilidades/Superdotação, inteligência e criatividade. Campinas: Editora Papirus, 2014. p. 219-264.

SAVI, R.; ULBRICHT, V.R. Jogos digitais educacionais: benefícios e desafios. Renote - Novas Tecnologias na Educação. v. 6, n. 2, 2008, p. 1-10. Disponível em: http://www.seer.ufrgs.br. Acesso em: 17 nov. 2016.

SHAMBLIN, M. Computer technology for the gifted and talented child! Focused investigation paper with research and personal experiences in educating students with computer technology. 2011. Disponível em: http://mrshamblin.pbworks.com/f/ ShamblinMichaelFocusedInvestigationPDF.pd. Acesso em: 06 jun. 2016.

VEEN, W; VRAKKING, B. Homo Zappiens: educando na era digital. Porto Alegre: Artmed, 2009.

Artigo recebido em: 21/06/2017

Aprovado em: 21/09/2017

\section{CONTATO PARA CORRESPONDÊNCIA:}

Ketilin Mayra Pedro.E-mail: ketilinp@yahoo.com.br 